\title{
Toxicidade de Extratos de Sementes de Jatropha curcas e Azadirachta indica à Plutella xylostella
}

Paulo V. Sousa, Flávio G. Jesus, Márcio S. Araújo, Fábio S. Matos \& Leandro Bacci

Avaliou-se a toxicidade de extratos de sementes de Azadirachta indica (Neen) e de Jatropha curcas (Pinhão manso) à Plutella xylostella (Traça das crucíferas). Discos foliares de couve (Brassica oleracea var. acephala) cultivar Portuguesa foram imersos nos extratos de Neen e Pinhão manso nas concentrações de 0,5 \% e, depois, fornecidos como alimento para as lagartas. Após isso, acompanhou-se o seu ciclo biológico. Todas as fases de desenvolvimento do inseto investigadas foram afetadas pela aplicação de óleos vegetais de A. indica e J. curcas. A aplicação de óleos vegetais de A. indica e J. curcas reduz a sobrevivência da praga.

Palavras-chave: Pesticida natural; Praga de Brassicaceae; Plantas inseticidas.

The aim of this study was to evaluate the toxicity of seed extracts of Azadirachta indica (Neen) and Jatropha curcas (Pinhão manso) to Plutella xylostella (Diamondback moth). Leaf discs of Portuguese Cabbage cultivar (Brassica oleracea var. Acephala) were immersed in extracts of Pinhão manso and Neen in concentrations of $0.5 \%$ and then provided as food for the moth. After this, followed up its biological cycle. All stages of development of this pest were affected by the application of vegetable oils of A. indica and J. curcas. The use of vegetable oils A. indica and J. curcas reduces survival of the pest.

Keywords: Natural pesticide; Brassicaceae pest; Plants insecticides. 


\section{Introdução}

A couve, Brassica oleracea var. acephala (L.), destaca-se entre as plantas hortícolas como um dos alimentos importantes na nutrição humana, sendo rica em minerais e vitaminas ${ }^{1}$. É uma cultura danificada por diversas pragas, tais como: pulgões, curuquerê da couve, lagarta-rosca, lagarta-mede-palmo e traça-dascrucíferas $^{2}$. Este último inseto, muitas vezes, limitante para o cultivo de crucíferas em áreas tropicais, em razão, principalmente, de seu ciclo curto e alto potencial reprodutivo, o que determina número anual elevado de gerações ${ }^{3}$.

O controle da traça-das-crucíferas é realizado geralmente com o uso de inseticidas organossintéticos. $\mathrm{O}$ uso intensivo desses produtos selecionou populações resistentes aos diferentes princípios ativos, comumente utilizados em seu controle ${ }^{4,5}$. Produtos naturais extraídos de plantas constituem-se fonte de substâncias bioativas compatíveis com programas de manejo integrado de pragas (MIP), o que pode reduzir os efeitos negativos, ocasionados pela aplicação descontrolada de inseticidas organossintéticos ao meio ambiente $e^{6,7,8}$.

As plantas inseticidas são capazes de provocar inibição alimentar nos insetos; redução da motilidade intestinal; interferência na síntese do ecdisônio; inibição da biossíntese da quitina; deformações em pupas e adultos, redução na fecundidade; longevidade; esterilização; inibição na oviposição e mortalidade de formas imaturas e adultas ${ }^{9,10,11,12,13}$. Algumas plantas inseticidas já foram avaliadas para o controle de $P$. xylostella. Chen e colaboradore ${ }^{14}$ encontraram que extratos de Melia azedarach (L.) causaram 93,5\% de redução na oviposição de $P$. xylostella na concentração de 4\%. Torres et al. (2001) verificaram que os extratos aquosos de Aspidosperma pyrifolium (Mart.), A. indica e Cissampelos aff. glaberrima (St. Hil.) reduziram a oviposição de $P$. xylostella, e que esta redução era diretamente correlacionada com o aumento das concentrações dos extratos dessas plantas e o efeito repelente se acentuava com a quantidade de substâncias bioativas extraídas e existentes em cada extrato. Boiça Junior e colaboradores ${ }^{12}$ verificaram que os extratos aquosos de Sapindus saponaria L., Trichilia pallida SW, Enterolobium contortisilliquum (Vell.) Morong e Nicotiana tabacum L. causaram $100 \%$ de mortalidade das larvas dessa praga. Medeiros e colaboradores ${ }^{6}$ constataram que os extratos de frutos de $S$. saponaria, e de E. contortisilliquum e de folhas de T. pallida, proporcionaram efeito deterrente na oviposição da praga, com índice de $100 \%$ de deterrência.

Portanto, tendo em vista a importância que representa o cultivo de brássicas e o uso de inseticidas botânicos dentro do manejo integrado de pragas, este trabalho teve por objetivo determinar o efeito de óleos vegetais de sementes de Azadirachta indica e Jatropha curcas sobre Plutella xylostella (L.) (Lepidoptera: Plutellidae).

\section{Material e Métodos}

Os experimentos foram desenvolvidos no Laboratório de Entomologia da Universidade Estadual de Goiás, Unidade Universitária de Ipameri. Para a criação da população de traça-das-crucíferas, usadas nesse trabalho, foram utilizadas plantas de couve, B. oleracea var. acephala, (Manteiga), semeadas em campo e, conduzidas sem qualquer tipo de aplicação de agrotóxico.

\section{CRIAÇÃO-ESTOQUE}

Para criação de P. xylostella, ovos deste inseto foram adquiridos do Laboratório de Resistência de Plantas a Insetos da FCAV - UNESP - Jaboticabal, SP. Lagartas recém-eclodidas foram confinadas em recipientes plásticos com dimensões $15,0 \times 10,0 \times 5,0 \mathrm{~cm}$, alimentadas com folhas de couve, previamente lavadas em água corrente.

Trocaram-se as folhas sempre que necessário, até que todos os insetos atingissem a fase de pupa. Essas foram coletadas diariamente e colocadas em tubos de vidro de fundo chato, medindo $1,0 \mathrm{~cm}$ de diâmetro, fechados com filme plástico transparente PVC com pequenos orifícios para circulação do ar. Após a emergência, coletaram-se os adultos diariamente. Foi feita a sexagem e formados dez casais, que permaneceram confinados em gaiolas plásticas, transparentes, circulares com uma abertura retangular vedada lateralmente com malha fina de nylon para possibilitar a circulação do ar. A parte superior da gaiola continha um orifício circular no qual foi colocada uma esponja embebida com uma solução de mel a 10\% para alimentação das mariposas adultas, presa com uma rolha de pano, tamponando tal abertura.

Dentro dessas gaiolas, foram colocados discos de 
folha de couve, medindo $8,0 \mathrm{~cm}$ de diâmetro sobre papel filtro umedecido, sobre um copo plástico de $50,0 \mathrm{ml}$ para a oviposição. Os discos foram substituídos diariamente e aqueles com as posturas, acondicionados em placa de Petri $(9,0 \mathrm{~cm}$ de diâmetro) até a eclosão das larvas, mantendo-se, então, os procedimentos já descritos.

\section{OBTENÇÃO DO EXTRATO HEXANO DE PINHÃO MANSO}

As sementes de $J$. curcas foram provenientes de plantio comercial, localizados na Cidade de Uberlândia, MG. Depois de trituradas, partes das sementes de $J$. curcas foram completamente mergulhadas em hexano a frio, obtendo-se, assim, os extratos, conforme metodologia proposta por Scramin e colaboradores ${ }^{16}$, até que os componentes da planta não mais eram transferidos por difusão ao solvente, conforme relatado Rey ${ }^{17}$, em que ocorre ausência de coloração do solvente, quando é trocado de dois em dois dias. O extrato obtido foi concentrado em evaporador rotativo à baixa pressão e temperatura reduzida $\left(<50^{\circ} \mathrm{C}\right)$ e, a quantidade obtida dele foi armazenada sob refrigeração para os testes biológicos. Quanto ao óleo de Neen, esse era uma formulação comercial, de nome Neen I GO ${ }^{\circledR}$.

\section{EFEITO DE ÓLEOS VEGETAIS NA BIOLOGIA DE P. XYLOSTELLA}

Para observação do desenvolvimento de P. xylostella, foram utilizadas placas de Petri $(9,0 \mathrm{~cm}$ de diâmetro), contendo folhas de couve - cv Manteiga, tratadas com os óleos na concentração de $0,5 \%$. Sobre cada folha, foram colocadas dez lagartas recém-eclodidas e, em seguida, foram vedadas com filme PVC para evitar fuga destas. Essas placas foram mantidas no laboratório em condições do ambiente, sendo as folhas substituídas diariamente por outras tratadas. Quando as folhas foram trocadas, anotou-se o número de larvas mortas. Tal procedimento foi adotado até que as larvas atingissem o estádio de pupa. As pupas sobreviventes foram pesadas 24 horas após a sua formação.

As variáveis biológicas avaliadas foram: duração e sobrevivência da fase larval e pupal, peso pupal e ciclo total. $\mathrm{O}$ delineamento estatístico adotado foi o inteiramente casualizados, com três tratamentos e dez repetições. Os dados dos experimentais foram analisados pelo teste de Tukey a 5\% de probabilidade e, para isso, utilizou-se o software ESTAT.

\section{Resultados e Discussão}

A duração da fase larval de $P$. xylostella foi prolongada quando as folhas de couve-comum utilizadas para sua alimentação foram tratadas com óleo vegetal a $0,5 \%$ de $J$. curcas. O óleo vegetal de $A$. indica proporcionou o melhor desempenho, no qual os insetos alimentados com folhas tratadas com este óleo vegetal não chegaram à próxima fase de desenvolvimento. A sobrevivência larval também foi afetada pelo óleo vegetal de $J$. curcas. Assim, apenas $11,0 \%$ das lagartas atingiram a fase de pupa, valor inferior ao registrado na testemunha com $80,0 \%$.

Quanto à duração da fase pupal, este parâmetro biológico também foi afetado, em que óleo vegetal a $0,5 \%$ de $J$. curcas $(5,37$ dias) provocou alongamento

Tabela 1. Média ( \pm EPM) de duração e sobrevivência das fases larval e pupal e peso de pupa de Plutella xyllostela em folhas de couve-comum tratadas com óleos $(0,5 \%)$ de sementes de Azadiracta indica e Jatropha curcas.

\begin{tabular}{|c|c|c|c|c|c|c|}
\hline \multirow[b]{2}{*}{ Tratamentos $^{1}$} & \multicolumn{2}{|c|}{ Fase Larval } & \multicolumn{4}{|c|}{ Fase Pupal } \\
\hline & $\begin{array}{l}\text { Duração } \\
\text { (dias) }\end{array}$ & $\begin{array}{c}\text { Sobrevivência } \\
(\%)\end{array}$ & $\begin{array}{l}\text { Duração } \\
\text { (dias) }\end{array}$ & $\begin{array}{c}\text { Sobrevivência } \\
(\%)\end{array}$ & $\begin{array}{l}\text { Peso Pupal } \\
\text { (mg) }\end{array}$ & $\begin{array}{l}\text { Ciclo Total } \\
\text { (dias) }\end{array}$ \\
\hline Testemunha & $5,02 \pm 0,14 \mathrm{a}$ & $80,00 \pm 5,96 \mathrm{a}$ & $4,83 \pm 0,09 \mathrm{a}$ & $70,00 \pm 4,71 \mathrm{a}$ & $5,10 \pm 0,14 \mathrm{a}$ & $14,43 \pm 0,37 \mathrm{a}$ \\
\hline A. indica & - & - & - & - & - & - \\
\hline J. curcas & $6,86 \pm 0,39 b$ & $11,0 \pm 4,58 \mathrm{~b}$ & $5,37 \pm 0,55 \mathrm{a}$ & $28,30 \pm 13,16 b$ & $5,20 \pm 0,27 \mathrm{a}$ & $17,70 \pm 0,28 b$ \\
\hline $\mathrm{F}$ & $8,02 * *$ & $5,48 * *$ & $0,91^{\mathrm{NS}}$ & $8,90 * *$ & $1,30^{\mathrm{NS}}$ & $48,43 * *$ \\
\hline C.V (\%) & 12,27 & 25,40 & 19,09 & 21,15 & 12,81 & 4,12 \\
\hline
\end{tabular}

${ }^{1}$ Médias seguidas da mesma letra na coluna, não diferem estatisticamente entre si, pelo teste de Tukey ao nível de $5 \%$ de probabilidade. Para análise, os dados foram transformados em $(\mathrm{x}+0,5)^{1 / 2}$. **Significativo a $1 \%$ de probabilidade.

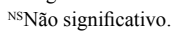


em relação à registrada na testemunha (4,83 dias). Do mesmo modo, ao constatado na fase larval, também na fase pupal, a sobrevivência foi reduzida pelo tratamento com óleo vegetal de J. curcas. Quanto ao peso de pupas, não houve diferença entre o tratamento óleo vegetal a $0,5 \%$ de $J$. curcas e a testemunha.

Em relação ao ciclo total, as folhas de couvecomum quando tratadas com óleo vegetal a $0,5 \%$ de J. curcas (17,70 dias) e utilizadas para na alimentação de P. xylostella, promoveram prolongamento no ciclo total da praga, quando comparado com a testemunha (14,43 dias).

De acordo com Torres e colaboradores ${ }^{15}$, o prolongamento da fase larval de $P$. xylostella, adicionalmente à mortalidade da fase larval, mediante aplicação de extratos vegetais, é muito importante em campo, pois aumentará o tempo de exposição da praga aos inimigos naturais, bem como o tempo médio de cada geração, reduzindo o crescimento populacional da praga. Mordue \& Blackwell ${ }^{10}$ também relataram que insetos tratados ou alimentados com azadiractina, inseticida regulador de crescimento de origem vegetal, apresentam inibição de crescimento, má-formação, prolongamento da fase larval e até morte das lagartas algumas horas após o tratamento.

O fato da aplicação de óleos vegetais de $A$. indica e $J$. curcas alterar o normal desenvolvimento e reduzir a sobrevivência de P. xylostella implica potencial de seu uso desses para o controle dessa praga.

\section{Agradecimentos}

À Equipe do Laboratório de Resistência de Plantas a Insetos da FCAV/UNESP de Jaboticabal (SP), que gentilmente cedeu algumas pupas para inicio de nossa criação da população de P. xylostella.

\section{Referências}

1. Filgueira, F.A.R. Novo Manual de Olericultura: Agrotecnologia Moderna na Produção e Comercialização de Hortaliças. 3 ed., Viçosa-MG: UFV, 2008.

2. Gallo, D.; Nakano, O.; Silveira Neto, S.; Baptista, G.C.; Berti Filho, E.; Parra, J.R.P.; Zucchi, R.A.; Alves, S.B.; Vendramim, J.D.; Marchini, L.C.; Lopes, J.R.S.; Omoto, C. Entomologia Agrícola. Piracicaba: FEALQ, 2002.
3. Ulmer, B.; Gillott, C.; Woods, C.; Erlandson, M. Crop Protection, 2002, 21, 327.

4. Castelo Branco, M.; Gatehouse, A.G. An. Soc. Ent. Bras., 1997, 26,75 .

5. Castelo Branco, M.; França, F.H.; Medeiros, M.A.; Leal, J.G.T. Hortic. Bras., 2001, 19, 60.

6. Medeiros, C.A.M.; Boiça Junior, A.L.; Torres, A.L.T. Bragantia, 2005, 64, 227.

7. Thuller, R.T.; Bortoli, S.A.; Goulart, R.M.; Pereira-Viana, C.L.T.; Pratissoli, D. Ciên. Agrotec., 2008, 32, 1154.

8. Zotti, M.J.; Grützmacher, A.D.; Grützmacher, D.D.; Castilhos, R.V.; Martins, J.F.S. Arq. Inst. Biol., 2010, 77, 111.

9. Schmutterer, H. Ann. Rev. Entomol., 1990, 35, 217.

10. Mordue, A.J.; Blackwell, A. J. Insec. Physiol., 1993, 39, 903.

11. Roel, A.R.; Vendramim, J.D.; Frighetto, R.T.S.; Frighetto, N. An. Soc. Entomol. Bras., 2000, 29, 799.

12. Boiça Junior, A.L.; Medeiros, C.A.M.; Torres, A.L.; Chagas Filho, N.R. Arq. Inst. Biol., 2005, 72, 45.

13. Araújo, MS.; Della Lucia, T.M.C.; Moreira, M.D.; Picanço, M.C. Rev. Bras. de Agroc., 2008, 14, 106.

14. Chen, C.; Chang, S.; Cheng, L.; Hou, R.F. J. Appl. Entomol., 1996, $120,165$.

15. Torres, A.L.; Barros, R.; Oliveira, J.V. Neotrop. Entomol., 2001, $30,151$.

16. Scramin, S.; Silva, H.P.; Fernandes, L.M.S.; Yhan, C.A. Nemat. Bras., 1987, 12, 121.

17. Rey, A.B. Química Tecnológica Fundamental. In: Física / Química Moderna. v.5, São Paulo: Fortaleza, 1970, 405p.

Paulo V. Sousa', Flávio G. Jesus', Márcio S. Araújo $^{2 *}$, Fábio S. Matos ${ }^{2} \&$ Leandro Bacci ${ }^{3}$

\footnotetext{
${ }^{1}$ Instituto Federal Goiano. Campus de Urutai, GO, 75790-000, Brasil

${ }^{2}$ UnU Ipameri, Universidade Estadual de Goiás, Ipameri, GO, 75780000, Brasil

${ }^{3}$ Departamento de Agronomia, Universidade Federal de Sergipe, São Cristóvão, SE, 49100-000, Brasil

*e-mail: marcio.araujo@ueg.br
} 